Short Communication

\title{
A Novel Waterborne Epoxy Coating with Anticorrosion Properties on Rusty Steel
}

\author{
Jiheng Ding ${ }^{2,3}$, Hongran Zhao ${ }^{1,2}$, Lin $\mathrm{Gu}^{2}$, Shengpei Su ${ }^{1, *}$, Haibin $\mathrm{Yu}^{2}$ \\ ${ }^{1}$ College of Chemistry and Chemical Engineering, Hunan Normal University, Changsha 410081, P. R. \\ China \\ ${ }^{2}$ Key Laboratory of Marine Materials and Related Technologies, Key Laboratory of Marine Materials \\ and Protective Technologies of Zhejiang Province, Ningbo Institute of Materials Technology and \\ Engineering, Chinese Academy of Sciences, Ningbo 315201, P. R. China \\ ${ }^{3}$ School of Chemical Engineering, Nanjing University of Science and Technology, Nanjing 210094, P. \\ R. China \\ *E-mail: $1107947901 @$ qq.com, sushengpei@yahoo.com, haibinyu@nimte.ac.cn
}

doi: $10.20964 / 2016.08 .08$

Received: 1 May 2016 / Accepted: 28 May 2016 / Published: 7 July 2016

This paper reports the synthesis of waterborne epoxy phosphate emulsion (WEP) through the reaction between epoxy resin E44 and phosphoric acid and ammonia neutralization. Synthesized WEP was characterized by FTIR for the confirmation of reaction between epoxy groups and phosphoric acid and SEM for morphology. WEP acted as a modifier in two-component epoxy anticorrosion coating on rusty steel substrate. The anticorrosion properties of the coating on rusty steel were investigated by electrochemical impedance spectroscopy (EIS) and Tafel polarization curve. Tafel polarization curve revealed that waterborne epoxy coating containing WEP had better protection ability which is clearly reflected by the protection efficiency $(96.6 \%)$. EIS study also showed the higher impedance value for WEP containing coating as compared to pure waterborne epoxy coating.

Keywords: Waterborne coatings; epoxy phosphate; anticorrosion; rusty painting

\section{FULLTEXT}

(C) 2016 The Authors. Published by ESG (www.electrochemsci.org). This article is an open access article distributed under the terms and conditions of the Creative Commons Attribution license (http://creativecommons.org/licenses/by/4.0/). 